\title{
Effect of spheroidizing heat treatment on the microstructure, hardness and toughness of high carbon powder metallurgy steel
}

\author{
O. Altuntaş ${ }^{1}$, A. Güral ${ }^{2 *}$ \\ ${ }^{1}$ Gazi University, Vocational School of Technical Sciences, Department of Machine and Metal Technologies, \\ Ankara, Turkey \\ ${ }^{2}$ Gazi University, Faculty of Technology, Department of Metallurgical and Materials Engineering, Ankara, Turkey
}

Received 1 December 2016, received in revised form 14 March 2017, accepted 15 March 2017

\begin{abstract}
Microstructure and toughness properties of high carbon powder metal steels, to which spheroidizing heat treatments were applied by using three different methods, were investigated. For this purpose, $1.4 \mathrm{wt} . \%$ natural graphite was added to NC100.24 pure iron powders. They were compacted under $700 \mathrm{MPa}$ pressure in the dimensions of $5 \times 10 \times 55 \mathrm{~mm}^{3}$ at room temperature in a mold in accordance with ASTM E-23 standard, and then they were sintered at $1180^{\circ} \mathrm{C}$ under shielding argon gas atmosphere. In sintered samples, primary cementite + lamellar pearlitic structures were produced. After sintering process, spheroidizing process was applied by using three different methods. First one of these methods was to expose samples to conventional spheroidizing heat treatment for $5-40 \mathrm{~h}$ at $705^{\circ} \mathrm{C}$ below $A_{\mathrm{c} 1}$ eutectoid temperature. By using the second method, the samples were subjected to spheroidizing process repetitively for 5 and $40 \mathrm{~h}$ in the temperature range of 705 and $735^{\circ} \mathrm{C}$ below and above the $A_{\mathrm{c} 1}$ eutectoid temperature. Thirdly, the samples quenched at $950^{\circ} \mathrm{C}$ were over-tempered for $0.5-5 \mathrm{~h}$ at 505 and $705^{\circ} \mathrm{C}$. It was understood that at the end of the spheroidizing process, there was no direct correlation between toughness and hardness but toughness was more correlated with the cementite distribution and morphology in the microstructure. After quenching, the spheroidized samples showed more superior toughness and hardness properties by using the over-tempering method.
\end{abstract}

K e y w or d s: spheroidizing heat treatment, powder metal steel, spherical cementite, toughness

\section{Introduction}

Porosity is commonly seen in materials produced by conventional powder metallurgy. However, it is well known that the pores adversely affect the mechanical properties because they cause a notch effect. Numerous properties of PM materials especially such as ductility, tensile strength, impact and fatigue are directly related to their pores, alloy elements and microstructure $[1,2]$. To increase the mechanical performance of the metal parts in porous structure produced by powder metallurgy (PM), quenching heat treatments are commonly used $[2,3]$. However, while these processes bring considerable hardness in steels, their pores cause a serious decrease in ductility [4]. On the other hand, it is known that ductility and strength properties of high carbon steels are significantly developed by the spheroidizing heat treatment [5]. The purpose of this heat treatment is to spheroidize the lamellar or continuously precipitated cementite phases in ferrite matrix structure. Spheroidizing heat treatment includes the conversion process of carbides into a spheroidal shape by annealing the carbon steels for a long time at about $A_{\mathrm{c} 1}$ temperature line [6]. In the steels with an initial microstructure as primary ferrite-pearlite or primary cementite-pearlite, it takes a long time considerably to spheroidize cementite. Additionally, over-tempering of steels with an initial martensitic microstructure provides the precipitation of spherical cementite particles $[7]$.

Spheroidized cementite particles can improve the strength, ductility and toughness of high carbon steels.

*Corresponding author: e-mail address: agural@gazi.edu.tr 

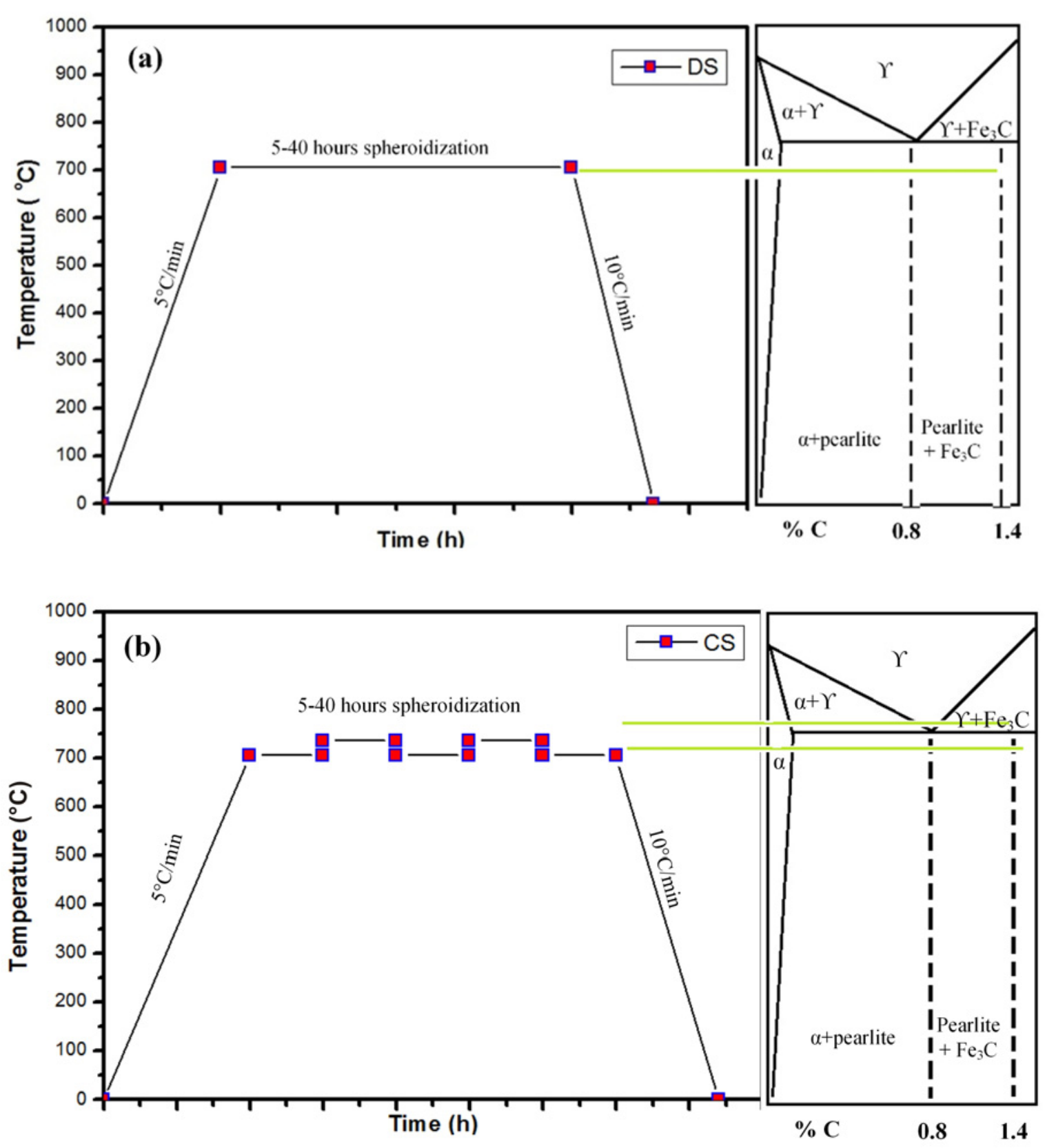

Fig. 1a, b. Schematic heat treatment cycle graphics of (a) DS and (b) CS.

More homogeneous dispersed spherical cementite in the fine ferrite grains brings excellent formability [8]. The spheroidizing process of cementite has been investigated by many researchers [9-11]. Plastic warm deformation can improve cementite spheroidizing in high carbon steel [9]. In their study, the spheroidizing process of cementite in commercial $\mathrm{Fe}-0.8 \mathrm{C}$ steel during cyclic heat treatment between 1173 and $923^{\circ} \mathrm{C}$ was investigated. Elongation values of commercial Fe-0.8C steel were improved by the spheroidizing process of cementite [10]. It is well known that conventional subcritical isothermal annealing takes a long time to spheroidize cementite $[12,13]$. Some inves- tigation results [14-20] have shown the potential of cyclic heat treatment techniques to accelerate cementite process [14]. Martensitic, bainitic, or fine pearlitic initial microstructures for acceleration of spheroidizing process were suggested by Hwang and Cooman [15]. It is noted that warm deformation accelerates the spheroidization of cementite [16]. In an annealed 0.6 wt.\% C steel, fine ferrite grains and spheroidized cementite could be produced by annealing at $810^{\circ} \mathrm{C}$ and subsequently exposing to air cooling [5]. Ultra-finegrained spherical cementite particles were produced by ECAP and multiple laser shock processing [17-19].

In this study, spheroidizing heat treatments were 

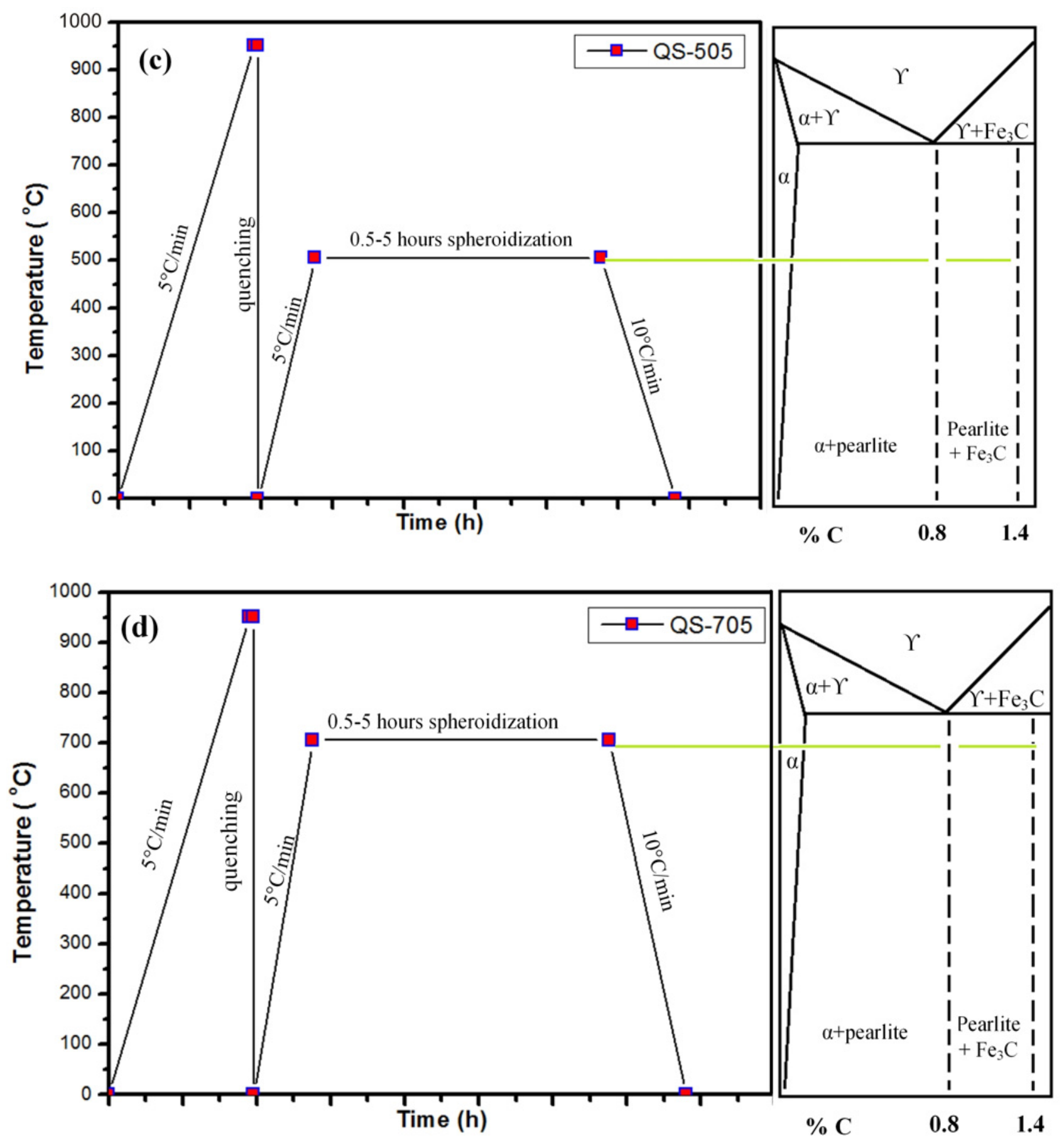

Fig. 1c, d. Schematic heat treatment cycle graphics of (c) QS-505 and (d) QS-705 samples.

applied to high carbon powder metallurgy steels according to different initial microstructures to develop especially their toughness resistance, and hardness-toughness relationships were established according to the spheroidization behavior of cementite phases.

\section{Experimental studies}

In the experimental study, 1.4 wt.\% natural graphite was added to Höganäs ${ }^{\mathrm{TM}}$ NC 100.24 pure iron powder to produce high carbon powder metal steel. These mixed powders were compacted in accordance with an ASTM-E23 standard via uniaxial pressing at room temperature under $700 \mathrm{MPa}$ to obtain $5 \times 10 \times 55 \mathrm{~mm}^{3}$ impact test sample. These samples were sintered in an argon gas atmosphere controlled furnace at $1180^{\circ} \mathrm{C}$ and powder metal samples with a density of $7.08 \mathrm{~g} \mathrm{~cm}^{-3}$ were produced.

In the sintered samples, three different spheroidiz- 
ing heat treatment cycles were applied. The first application was the conventional spheroidizing process; the isothermal spheroidizing annealing was applied to the sintered samples directly at $705^{\circ} \mathrm{C}$ for $5-40 \mathrm{~h}$ as schematically shown in Fig. 1a and these samples were coded as DS. The second group of sintered samples was spheroidized cyclically for a total period of $5 \mathrm{~h}$ by being kept for 1 hour in the temperature range of 705 and $735^{\circ} \mathrm{C}$ below and above the $A_{\mathrm{c} 1}$ eutectoid temperature as schematically shown in Fig. 1b and similarly for a total period of $40 \mathrm{~h}$ by being kept for $8 \mathrm{~h}$ in this temperature interval. The samples to which this process was applied were coded as CS. The last group of samples was austenitized at $950{ }^{\circ} \mathrm{C}$ for $6 \mathrm{~min}$, a martensitic structure formed by quenching and then they were isothermally annealed at $505^{\circ} \mathrm{C}$ for $0.5-5 \mathrm{~h}$ (Fig. 1c) and they were coded as QS-505. Similarly, as schematically shown in Fig. 1d, the samples were austenitized at $950^{\circ} \mathrm{C}$ for $6 \mathrm{~min}$, and after the quenching process, spheroidizing process was applied at $705^{\circ} \mathrm{C}$ for $0.5-5 \mathrm{~h}$ and the samples were coded as QS-705.

To reveal the microstructures in all the samples, exemplary metallographic processes were applied, and they were etched with $2 \%$ Nital solution. In imaging of microstructure, JEOL JSM-6060LV Scanning Electron Microscope (SEM) was used selecting secondary electron imaging mode. Vickers hardness measurements of the samples were determined by using a 2-kg load in Shimadzu HMV-2 hardness device, and the HV2 mean values were found by taking a hardness value from at least 5 different points for each sample.

For tests of Charpy impact samples that were prepared in accordance with ASTM E-23 standard were performed at room temperature in Instron-Wolpert Impact testing device with anvil capacity of $150 \mathrm{~J}$. In impact toughness experiment, at least 3 samples were used for each heat treatment. The mean of the data obtained was calculated, and the impact toughness graphics were obtained.

\section{Experimental results and discussion}

As seen in Fig. 2, initial microstructures of DS and CS samples were primary cementite plus pearlite. Initial microstructures of QS samples were completely martensitic (Fig. 3). In Fig. 2, the presence of typical dense pearlite colonies and primary cementite (shown with an arrow) is clearly seen. Figure 3 shows the plate martensitic structure in the microstructure that was obtained by quenching from the austenite phase. For the spheroidizing process to be applied, there were pores (dark regions as seen in Figs. 2 and 3), which were natural properties of the powder metal samples, in both initial microstructures.

Figures 4 and 5 show the microstructures of DS and

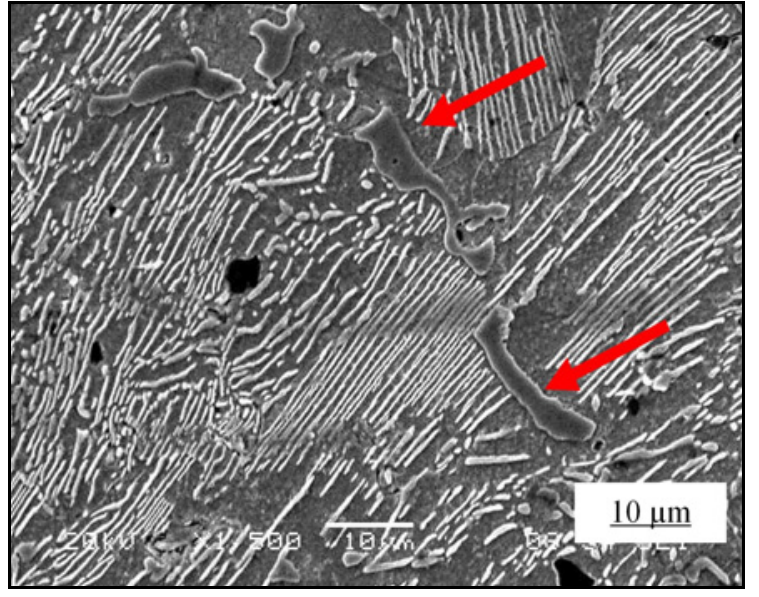

Fig. 2. SEM microstructure image of the sintered sample.

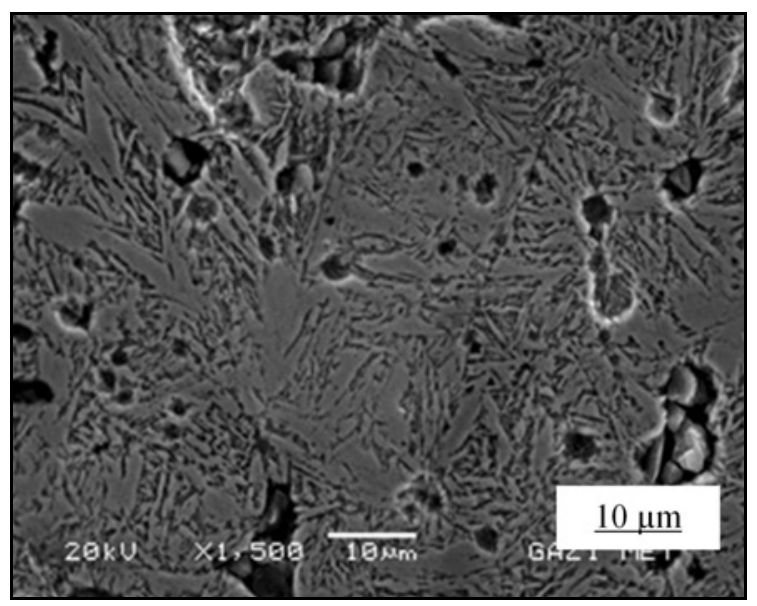

Fig. 3. SEM microstructure image of the quenched sample.

CS samples, respectively. As is seen in Figs. 4a,b it is obvious that the cementite lamellas in the pearlitic structure were not completely spheroidized yet at the end of 5 and $40 \mathrm{~h}$ spheroidizing period. However, Fig. 4a shows the presence of spheroidized cementite particles as well as the areas that were not affected by spheroidization. As can be understood from these microstructures, spheroidization trends of cementite in powder metal steels having simple carbon composition in ferrite matrix did not start at an equal rate in every area. This result showed that there could be different driving force areas within the structure in DS sample in order to spheroidize the cementite phases. The possible reason can be the difference in accumulated (stored) energy due to the density difference caused by the single-acting press process. Previous studies revealed that cementite was required to be isothermally annealed for a long time such as $72 \mathrm{~h}$ at $680-700^{\circ} \mathrm{C}$ for spheroidization in steels having a eutectoid carbon composition $[12,13]$. 

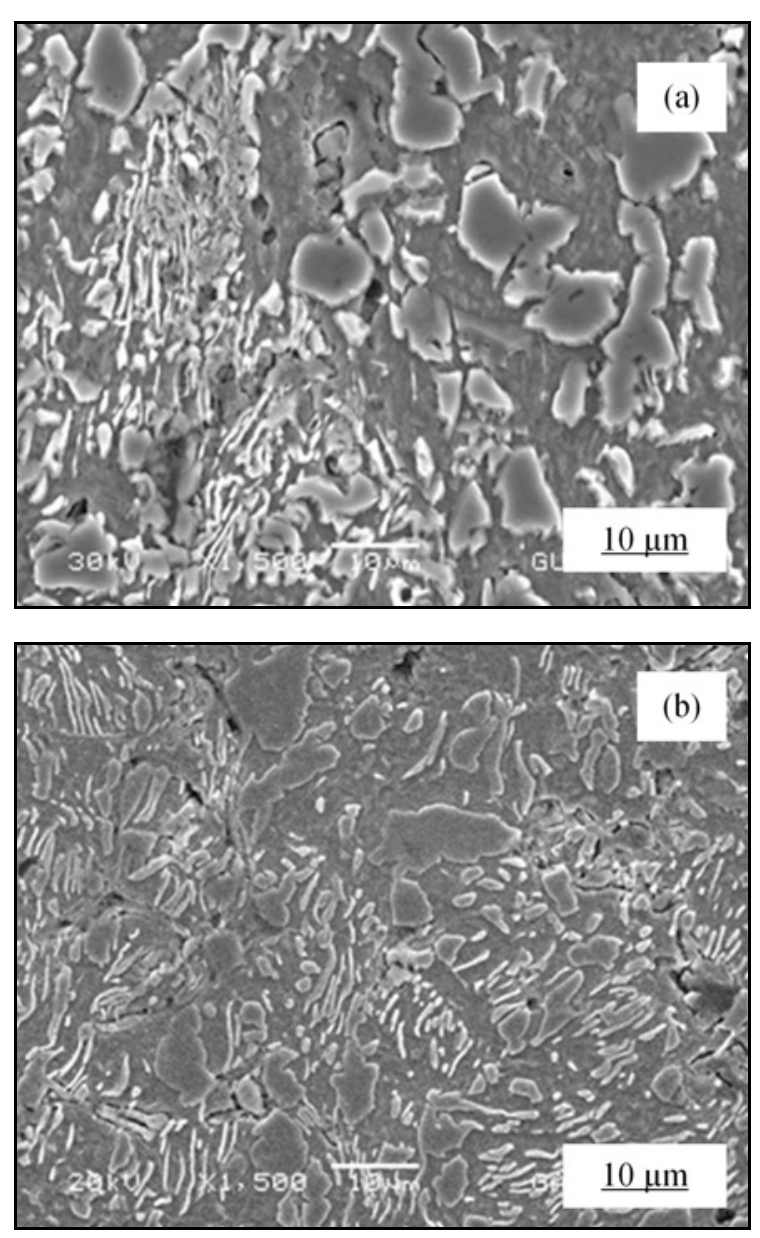

Fig. 4. SEM microstructure images of DS samples obtained at the end of (a) $5 \mathrm{~h}$ and (b) $40 \mathrm{~h}$ spheroidization time.

Figures 5a,b show microstructures of CS samples spheroidized for 5 and $40 \mathrm{~h}$, respectively. As is seen in Fig. 5a, cementite phases were not completely spheroidized at the end of $5 \mathrm{~h}$ isothermal holding in CS samples; however, in Fig. 5b it can be observed that lamellar cementite started to break down in the microstructure at the end of $40 \mathrm{~h}$, but spheroidization was not totally completed. When the spheroidized microstructure results of DS and CS samples are examined, it can be asserted that the time required for an efficient spheroidization was longer than $40 \mathrm{~h}$. The possible reason for this can be associated with the fact that a great part of the energy required for spheroidization of cementite in the sample kept at spheroidizing temperature was consumed for ongoing sintering. Thus it was thought that the time required for the spheroidization of cementite might remain insufficient.

Figures 6 and 7 show microstructures of QS-505 and QS-705 samples, respectively. In Fig. 6, when the microstructure of QS-505 sample was examined after isothermal annealing at $505^{\circ} \mathrm{C}$ for 0.5 and $5 \mathrm{~h}$, it was
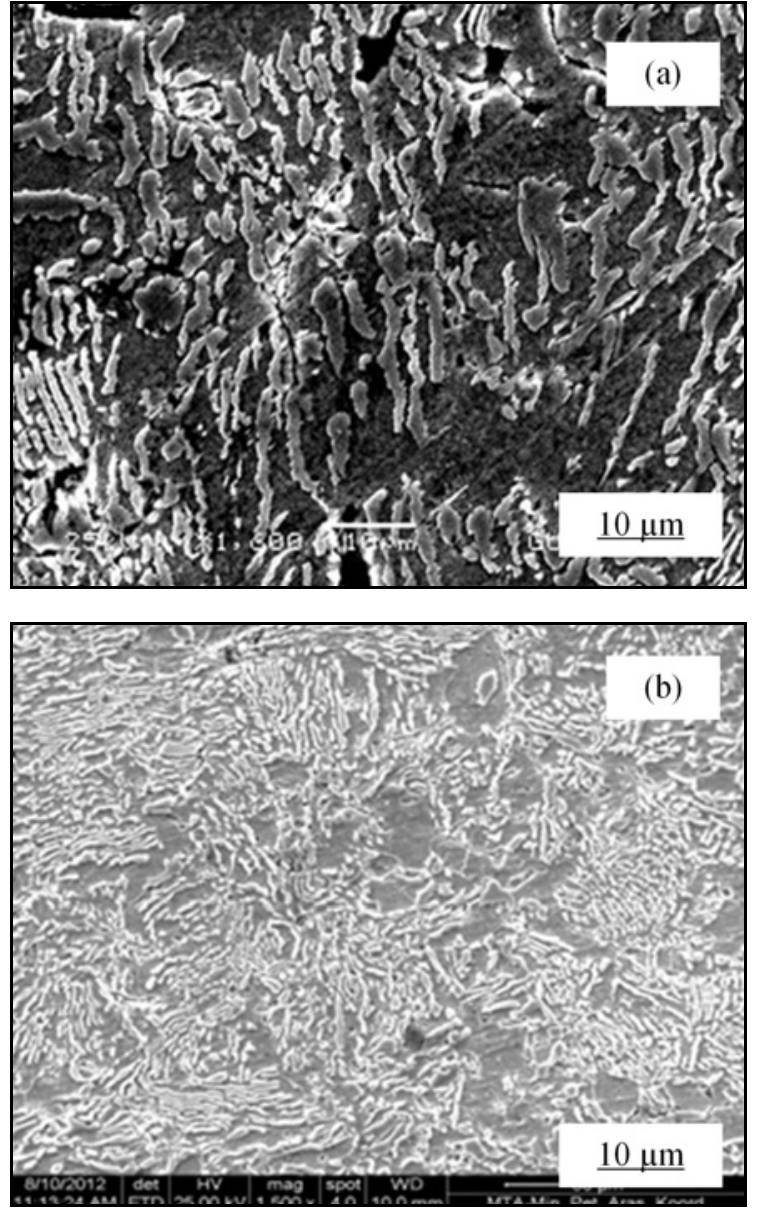

Fig. 5. SEM microstructure images of CS samples obtained at the end of (a) $5 \mathrm{~h}$ and (b) $40 \mathrm{~h}$ spheroidization time.

understood that acicular shapes of martensite plates started to degrade partially, but cementite particles did not occur significantly. However, it was clearly seen that spherical cementite started to form as a result of $5 \mathrm{~h}$ isothermal annealing. Figures $7 \mathrm{a}, \mathrm{b}$ show the microstructures of QS-705 samples spheroidized by isothermal annealing at $705^{\circ} \mathrm{C}$ for 0.5 and $5 \mathrm{~h}$, respectively. It was observed that in these samples, martensite plates completely disappeared after quenching and very thin and relatively spherical cementite particles formed in a ferritic matrix. It is known that dislocation intensity of high amount is found between martensite plates, which increases potential nucleation number required for cementite. Furthermore, the formation of many fine cementite particles accelerates due to an excess free energy difference between martensite and cementite phases [20].

Depending on the increasing spheroidization time, it was observed that spherical cementite particles lost their fine-grained structure and they became coarse. It could be thought that nucleation and growth mechanisms in spherical cementite particles produced in 

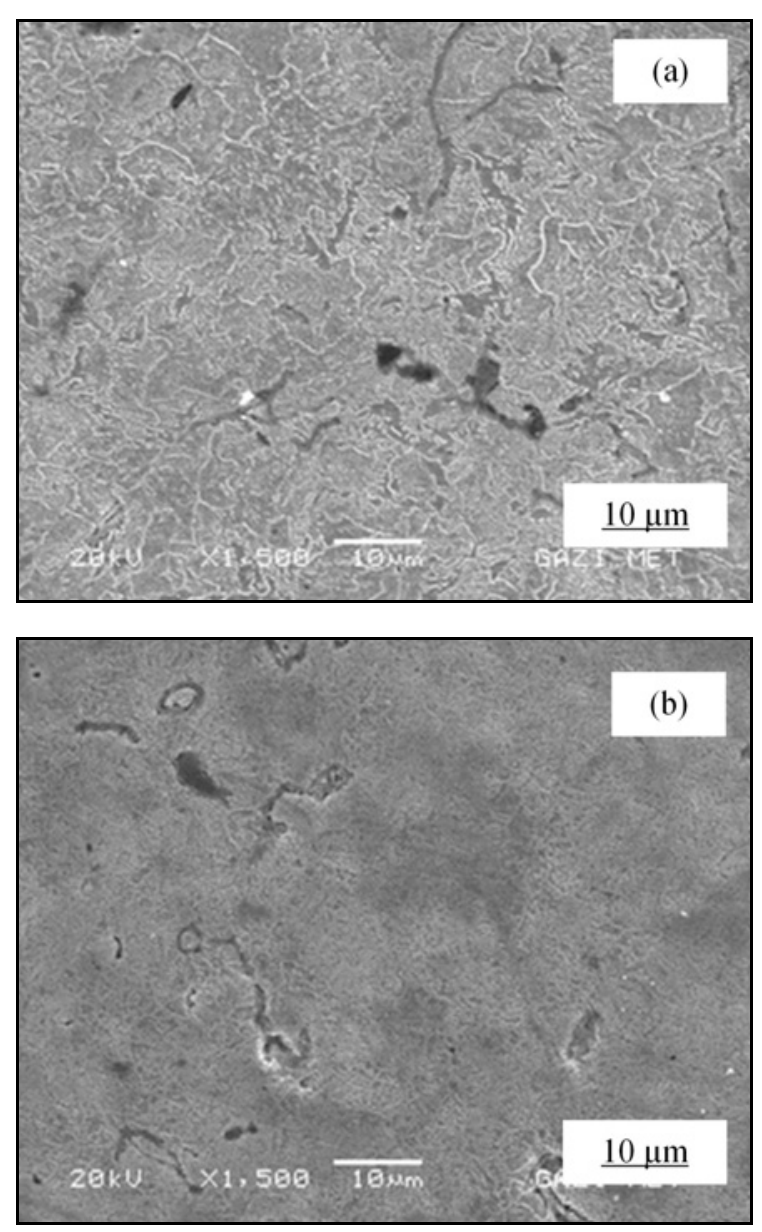

Fig. 6. SEM microstructure images of the spheroidized QS-505 series samples with different holding time (a) $0.5 \mathrm{~h}$, (b) $5 \mathrm{~h}$.

QS-series materials were different for DS and CS series materials. As in these samples, cementite nucleates mostly between the martensite plates having high dislocation density, whereas spheroidization of cementite under balance conditions in DS and CS samples was realized by reducing ferrite/cementite interfacial tension without nucleation. Thus, it is seen that a long time was required for spheroidization of cementite in DS samples. At the same time, in QS series samples, the activation energy in the formation of cementite was relatively low which accelerated the formation of cementite from the martensitic phase. On the other hand, another factor that increased the reaction rate was temperature. Therefore, the formation of spherical cementite particles was observed as a result of $5 \mathrm{~h}$ isothermal annealing in QS sample. Also, it was essential to have the surface tension energy higher than the main structure to spheroidize the cementite. Because lower activation energy was required for cementite formation in QS sample, spheroidization forms more and faster cementite phases. Additionally, balanced primary cementite phases after sintering in DS sam-
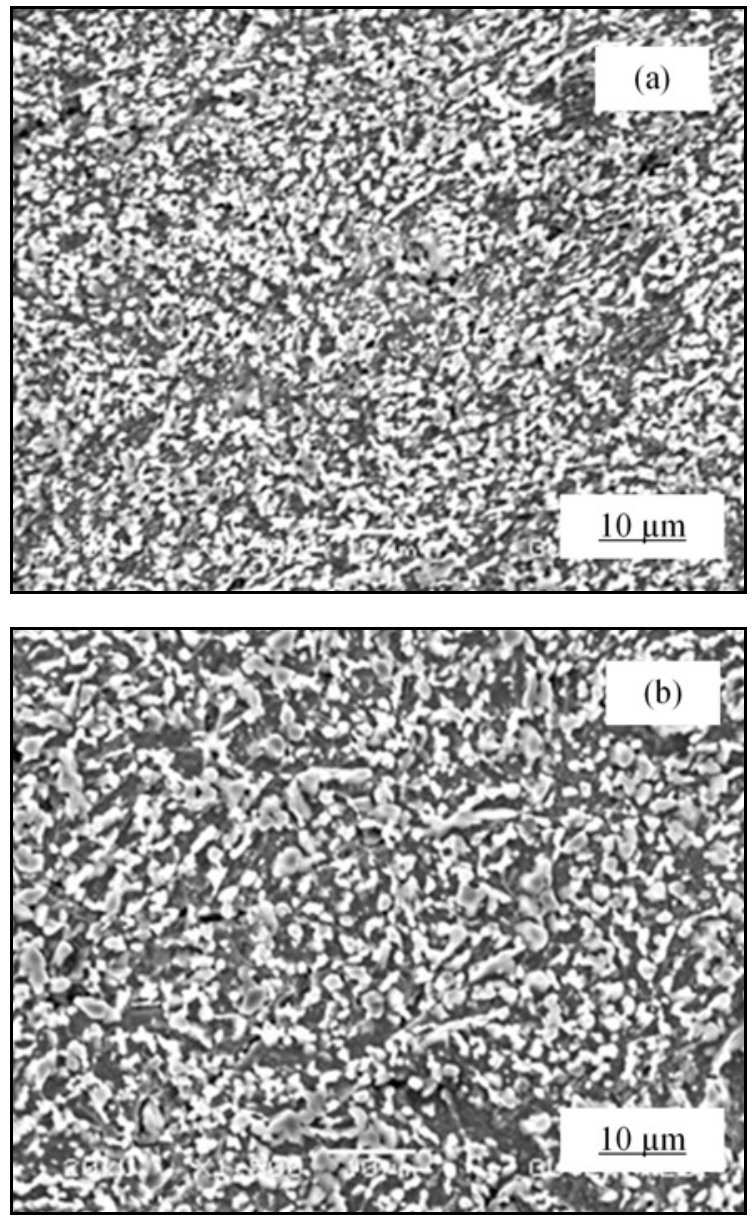

Fig. 7. SEM microstructure images of the spheroidized QS-705 series samples with different holding time (a) $0.5 \mathrm{~h}$, (b) $5 \mathrm{~h}$.

ple precipitated as an allotriomorphic grain boundary. Then, since the heat energy given during isothermal annealing applied for spheroidization of cementite was possibly spent for the interface energy, wetting angle increased, and secondary cementite particles within the grain precipitated in the form of a spheroid. However, the energy and time required for this formation reached high values. Thus spheroidization took quite a long time in DS and CS series samples.

Figure 8 shows the hardness of the samples graphically. Numerous properties of the materials such as their macro hardness values are directly correlated with their microstructural properties. In this study, it can be asserted that general hardness values of the samples were lower than expected. However, as especially in powder metal materials, the porosity causes to obtain lower values than the real values. Among the samples, the significant superiority of QS-505 sample regarding hardness was observed when compared to others. However, this was caused by the initial martensitic structure of the sample as a result of quenching. Hardness values decreased in QS-series materials as a 


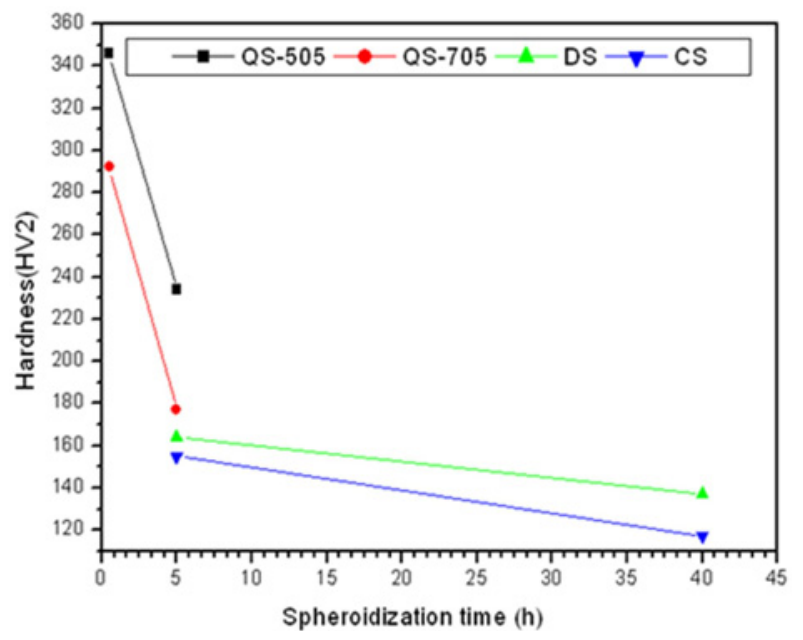

Fig. 8. Hardness graphic of QS-505, QS-705, CS and DS samples.

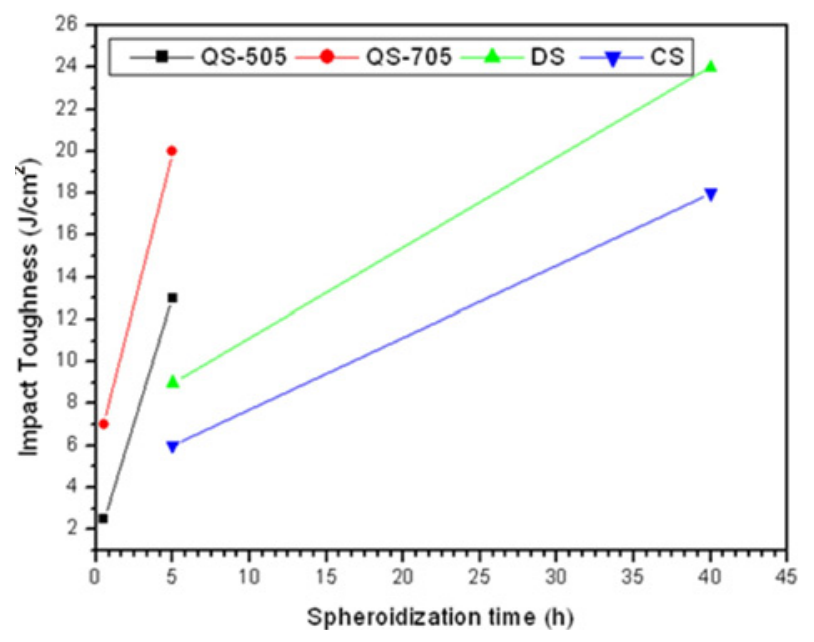

Fig. 9. Toughness graphic of QS-505, QS-705, CS and DS samples.

result of increased isothermal annealing temperature and annealing period.

When $5 \mathrm{~h}$ spheroidization period was considered in all the samples, it can be clearly understood from the hardness graphics in Fig. 8 that the hardness of QS-705 sample that was completely spheroidized was higher than that of DS and CS samples.

In this study, it is intended to provide discontinuity of solid secondary phases such as cementite in the microstructure to reduce the brittleness of materials. Due to spheroidization of cementite phases without connection between them, the toughness of the material could be developed without significant decrease of the hardness of the material. Figure 9 shows impact toughness graphics of QS, DS and CS series samples. Whereas minimum impact toughness was obtained after $0.5 \mathrm{~h}$ annealing in QS-505 sample with an approximate value of $2.5 \mathrm{~J} \mathrm{~cm}^{-2}$, the highest impact toughness value was obtained in DS sample after $40 \mathrm{~h}$ spheroidizing heat treatment $\left(24 \mathrm{~J} \mathrm{~cm}^{-2}\right)$. This was followed by the QS-705 sample in which an ideal spheroidization was provided with the value of $20 \mathrm{~J} \mathrm{~cm}^{-2}$. On the other hand, it was observed that QS-505 sample was superior regarding high hardness/toughness ratio. It was observed that unrelated spherical cementite particles obtained at the end of $5 \mathrm{~h}$ in QS samples made a positive contribution to the optimization of hardness/toughness properties. As a result of the present study, in high carbon powder metal steel, it was found that the spheric cementite size and morphology were important parameters in controlling the hardness and impact toughness properties.

\section{Conclusions}

In this study, high carbon PM steels were produced by using powder metallurgy method. Three different spheroidizing heat treatment cycles were applied. Following results were obtained:

1. Cementite lamellas in the pearlitic structure of the high carbon powder metal steels were not completely spheroidized at the end of 5 and $40 \mathrm{~h}$ current spheroidizing period. However, it can be concluded that using spheroidization time below $40 \mathrm{~h}$ may be better.

2. Spheroidization trends of cementite in powder metal specimens having carbon composition in ferrite matrix did not start at an equal rate in every area. This result showed that there could be different driving force areas within the structure in the sintered sample to spheroidize the cementite phase.

3. The microstructure of QS-505 sample with acicular shapes of martensite plates started to degrade partially for $0.5 \mathrm{~h}$ holding time, but cementite formation was not significant. However, it was clearly seen that spherical cementite started to form as a result of $5 \mathrm{~h}$ isothermal annealing.

4. In microstructures of QS-705 samples, the martensite plates completely disappeared and very thin and relatively spherical cementite particles formed and distributed uniformly in the ferritic matrix.

5. It was observed that QS-505 sample was superior in terms of high hardness/toughness ratio. It was observed that unrelated spherical cementite particles obtained at the end of $5 \mathrm{~h}$ in QS samples made a positive contribution to the optimization of hardness/toughness properties.

\section{References}

[1] Wu, M., Tsao, L., Shu, G., Lin, B.: Mater. Sci. Eng. A, 538, 2012, p. 135. doi:10.1016/j.msea.2011.12.113 
[2] Wu, M. W., Tsao, L. C., Chang, S. Y.: Mater. Sci. Eng. A, 565, 2013, p. 196. doi:10.1016/i.msea.2012.12.032

[3] Tekeli, S., Güral, A.: Materials \& Design, 28, 2007, p. 1353. doi:10.1016/i.matdes.2006.01.022

[4] Allison, P. G., Horstemeyer, M. F., Hammi, Y., Brown, H. R., Tucker, M. T., Hwang, Y.-K.: Mater. Sci. Eng. A, 529, 2011, p. 335. doi:10.1016/i.msea.2011.09.037

[5] Saha, A., Mondal, D. K., Maity, J.: Mater. Sci. Eng. A, 527, 2010, p. 4001. doi:10.1016/i.msea.2010.03.003

[6] Monia, S., Varshney, A., Gouthama Sangal, S., Kundu, S., Samanta, S., Mondal, K.: Journal of Materials Engineering and Performance, 24, 2015, p. 4527. doi:10.1007/s11665-015-1726-4

[7] Altuntaş, O.: Investigation of Spheroidization Heat Treatment Effects on Microstructure and Impact Toughness Properties of High Carbon Powder Metal Steels. [Master Thesis]. Ankara, Gazi University Institute of Science and Technology 2013.

[8] Wang, B., Liu, Z. Y., Zhou, X. G., Wang, G. D.: Journal of Iron and Steel Research, 20, 2013, p. 25. doi:10.1016/S1006-706X(13)60107-7

[9] Wu, T., Wang, M. Z., Gao, Y. W., Li, X. P., Zhao, Y. C., Zou, Q.: Journal of Iron and Steel Research, 19, 2012, p. 60. doi:10.1016/S1006-706X(12)60140-X

[10] Lv, Z. Q., Wanga, B., Wang, Z. H., Sun, S. H., Fu, W. T.: Mater. Sci. Eng. A, 574, 2013, p. 143. doi:10.1016/j.msea.2013.02.059
[11] Yi, H. L., Hou, Z. Y., Xu, Y. B., Wu, D., Wang, G. D.: Scripta Materialia, 67, 2012, p. 645. doi:10.1016/j.scriptamat.2012.07.020

[12] Tianand, Y. L., Kraft, R. W.: Metallurgical Transactions A, 18, 1987, p. 1403. doi:10.1007/BF02646654

[13] Mondaland, D. K., Dey, R. M.: Trans. IIM, 37, 1984, p. 351.

[14] Lü, Z. Q., Zhang, H. F., Meng, Q., Wang, Z. H., Fu, W. T.: Journal of Iron and Steel Research, 23, 2016, p. 145. doi:10.1016/S1006-706X(16)30026-7

[15] Hwang, H., Cooman, B. C. D.: Steel Research International, 87, 2016, p. 112. doi:10.1002/srin.201400591

[16] Storojeva, L., Ponge, D., Kaspar, R., Raabe, D.: Acta Materialia, 52, 2004, p. 2209. doi:10.1016/j.actamat.2004.01.024

[17] Xiong, Y., He, T., Guo, Z., He, H., Ren, F., Volinsky, A. A.: Mater. Sci. Eng. A, 563, 2013, p. 163. doi:10.1016/i.msea.2012.11.068

[18] Shin, D. H., Han, S. Y., Park, K. T., Kim, Y. S., Paik, Y. N.: Materials Transactions, 44, 2003, p. 1630. doi:10.2320/matertrans.44.1630

[19] Xiong, Y., He, T., Ren, F., Li, P.-Y., Chen, L. F., Volinsky, A. A.: Journal of Iron and Steel Research, 22, 2015, p. 55. doi:10.1016/S1006-706X(15)60009-7

[20] Ata, K. G., Meisam, S. A.: Journal of Iron and Steel Research, 17, 2010, p. 45. doi:10.1016/S1006-706X(10)60085-4 